\title{
Untangling the Main Components of Hydromorphological Alteration In Greek Rivers
}

\author{
Konstantinos Stefanidis *, Konstantinos Gritzalis, Theodora Kouvarda, Anna Latsiou, Anastasia \\ Lampou and Elias Dimitriou*
}

Hellenic Centre for Marine Research, Institute of Marine Biological Resources and Inland Waters, $46.7 \mathrm{~km}$ of Athens-Sounio Ave., 19013 Anavyssos, Attiki, Greece

* Correspondence: kstefanidis@hcmr.gr; Tel.: +30-229-107-6439

\begin{abstract}
The Water Framework Directive (WFD) requires from member states to monitor hydromorphological features of rivers in order to assess their ecological quality. Thus, numerous hydromorphological assessment methods have been developed with most of them focusing on the dynamics of hydrology, geomorphology and riparian zone extent. Within the scope of this study, we assessed the hydromorphological features of 106 river reaches distributed among fourteen WFD River Basin Districts (RBDs) to identify the main drivers of hydromorphological perturbation. We employed the River Habitat Survey (RHS) and we recorded hydromorphological features and modifications in both banks and the channel bed along $500 \mathrm{~m}$ for each reach. Then, the Habitat Modification Score (HMS) and the individual sub-scores that indicate the extent of specific modifications (e.g., bridges, fords, weirs, bank reprofiling, bank reinforcement etc) were calculated in order to a) assess the severity of the total artificial modification and b) to highlight the most common and severe causes of longitudinal and cross-sectional alterations. The results showed that alterations such as reprofiling and reinforcement of banks, contributed the most to the total HMS followed by the presence of fords and bridges. Particularly the bank alterations indicate a serious deterioration of the longitudinal profile of the reaches while the occurrence of many fords and bridges is the main cause for perturbations that affect the stream cross-sectional profile. Overall, these results compile a first nationwide assessment of the hydromorphological status of Greek rivers in line with the WFD and set the basis for further research that will focus on the diversity of stream habitat features as a measure for the overall ecological quality.
\end{abstract}

Keywords: rivers; hydromorphology; RHS; WFD; bank modifications

\section{Introduction}

Riverine ecosystems of Europe are inarguably under threat of multiple stressors, with nutrient pollution and hydromorphological alteration being the most common and serious causes for ecological degradation [1-3]. Changes in the hydromorphology in particular, are linked with the destruction of floodplains and riparian areas which lead to habitat loss and biodiversity decline [2]. Not surprisingly, numerous hydromorphological assessment methods have been developed, with most of them focusing on the dynamics of hydrology, geomorphology and riparian zones, in order to evaluate the severity and the extent of the hydromorphological degradation [4]. Since hydromorphological alteration is considered one of the main causes for European rivers failing to achieve a "Good Ecological Status" [5], it is obvious that member states will have to strengthen the monitoring activities and develop more efficient tools and methods for detecting and analyzing the drivers of hydromorphological perturbation.

The introduction of Water Framework Directive (WFD) has offered the opportunity to better understand the relationships between hydromorphology and ecology in European rivers [6]. At the same time, the WFD dictates to all member states to monitor all Community waters with the scope of establishing objectives to avert further status deterioration and to achieve a "Good Status" by 2021.

In Greece, the monitoring of the biological quality elements (BQEs), the physicochemical and the hydromorphological conditions of all running waters in compliance with the WFD is implemented 
by the Institute of Marine Biological Resources and Inland Waters (IMBRIW) of Hellenic Centre for Marine Research (HCMR). The sampling network extends to the whole national territory and is distributed among fourteen WFD River Basin Districts (RBDs) [7]. Hydromorphological features and modifications of the sites of the sampling network are recorded once for the duration of the monitoring period according to the River Habitat Survey (RHS) method. In this study, we examined preliminary results of the hydromorphological assessment for a subset of monitoring stations to identify and explore spatial patterns of the hydromorphological modifications at reach scale. This work is a first nationwide assessment of the hydromorphological status of Greek rivers in line with the WFD that will set the basis for further research on the relationships between hydromorphological modifications, diversity of stream habitat features and ecological responses, with significant implications for developing new methods and indices for rapid assessments of hydromorphological status.

\section{Methods}

\subsection{Samplings and data collection}

The RHS protocol was filled for 106 reaches of the national monitoring network during the summer (low flow period) of 2018 and 2019. The studied reaches are distributed among 14 River Basin Districts (RBDs). The Habitat Modification Score (HMS), which is an indicator of the artificial modification of the reach [8], and the individual sub-scores that indicate the extent of specific modifications (e.g. bridges, fords, weirs, bank reprofiling, bank reinforcement etc) were calculated in order to assess the severity of the total artificial modification and to identify the most common and severe modifications.

\subsection{Data analysis}

A principal component analysis (PCA) was conducted for the habitat modification sub-scores to identify the modifications that explain the most variation in our data and to explore for gradients of key hydromorphological alterations. The PCA was conducted with the "FactoMineR" package [9], in $R$ environment [10].

\section{Results and Discussion}

Our results showed that the Bridges sub-score had the largest contribution to the total HMS (more than 20\%) for all the examined reaches (Figure 1), followed by the Banks and Bed Resectioning, the Fords and the Bank Reinforcement sub-scores. This finding is confirmed by the results of the PCA (Figure 2) where it is shown that the presence of fords, the banks and bed resectioning, the channel realignment and the presence of bridges had the largest contribution to the first two principal components. The first two components of the PCA accounted for a substantial share of the total variance $(28.7 \%)$. When examining further the results of the PCA, the description of the dimensions (Figures $2 \& 3$ ) showed that bank and bed resectioning and channel realignment contributed the most to component 1 . In contrast, the presence of bridges and fords had the largest contribution to component 2. These results may indicate a gradient of longitudinal modifications across the reach along the PC1 where resectioning coincides with channel realignment, whereas PC2 may suggest a gradient of cross-sectional modifications highlighted by the presence of bridges and fords and the reinforcement of banks and the channel bed that usually occurs with the construction of artificial inchannel features.

Thus, our findings highlight that man-made transverse structures and features, such as bridges and fords, and longitudinal modifications, namely channel and bed resectioning, play a major role in defining the total hydromorphological alterations at local river segment scale. These results agree with other previously published studies that have highlighted bank resectioning and reinforcement as main sources of hydromoprhological alteration in 79 river sites from 5 different EU countries [11]. Bank resectioning is usually associated with channel realignment [8] and is used for producing more uniform channel forms that facilitate flood flows. Thus, bank and channel resectioning involves 
modifications that are part of flood defence management practices that usually protect neighboring agricultures from flood events. On the other hand, bank reinforcement includes modifications that protect banks from erosion, using hard materials (concrete, bricks, rip-rap etc) as artificial substrate for banks and bed. Here we showed that bank reinforcement is associated with the presence of bridges, thus we assume that reinforcement of both banks and bed occurs because of the construction of bridge structures and components (foundations, piers, abutments, etc).

By further examining the PCA biplot (Figure 4), we can distinguish the most impaired sites (Group 5: severely modified) grouped along the vectors of RS and RA, while the sites that are significantly modified (Group 4) are mostly located between the vectors of RI and RA. Obviously modified sites (Group 3) showed a preference for the vector of Bridges HMS sub-score. These observations imply that bank and bed resectioning and realignment are closely related with the severe modifications while at moderately impaired river reaches bridges appear to be the dominant cause for hydromorphological alteration.

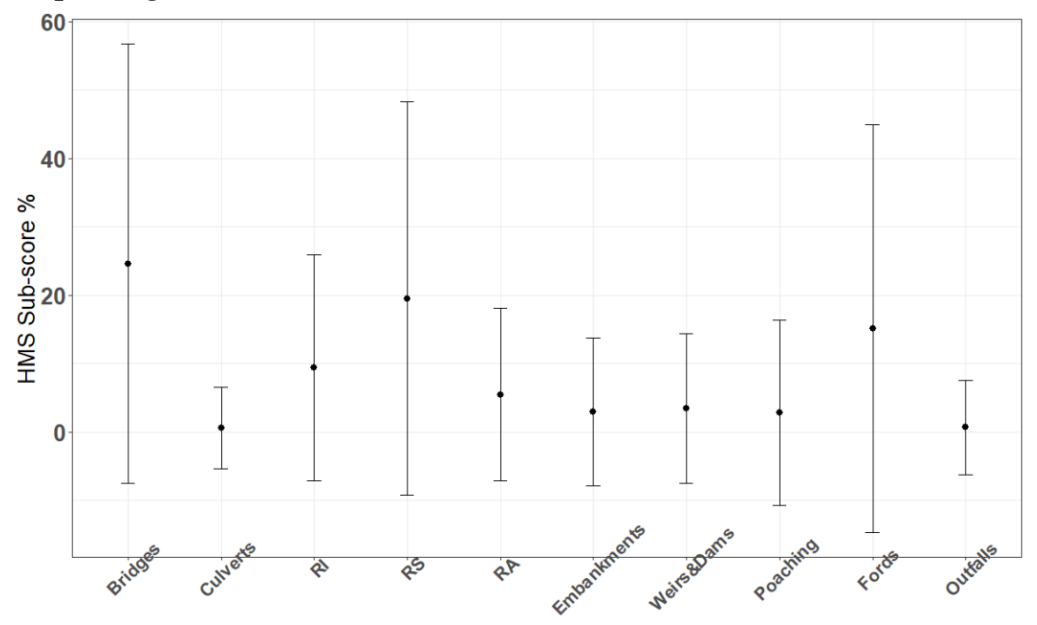

Figure 1. Error bars showing the mean value and the standard error of each HMS subscore for all the studied reaches. RI means Bank Reinforcement, RS means Banks and Bed Resectioning and RA means Banks and Bed Realignment.
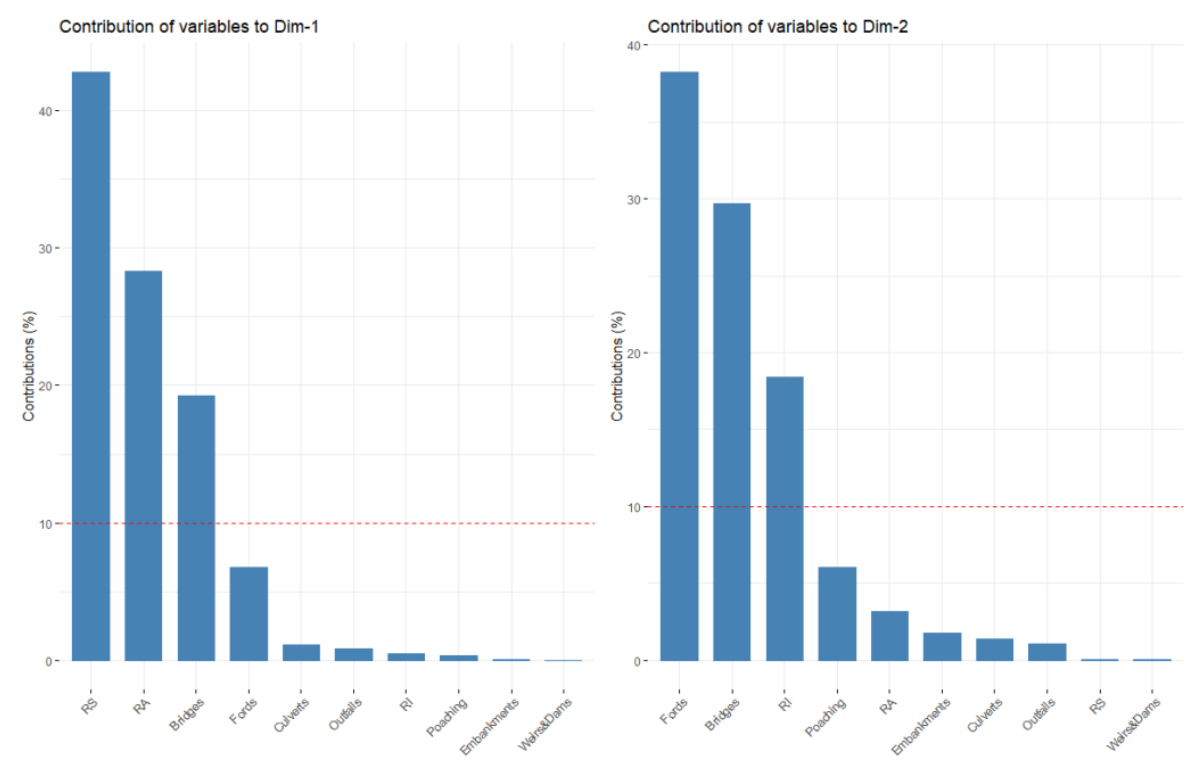

Figure 2. Bars show the \% contribution of each HMS sub-score to components 1 and 2 of the PCA. The red dashed line in each graph indicates the expected average contribution. RI means Bank Reinforcement, RS means Banks and Bed Resectioning and RA means Banks and Bed Realignment. 


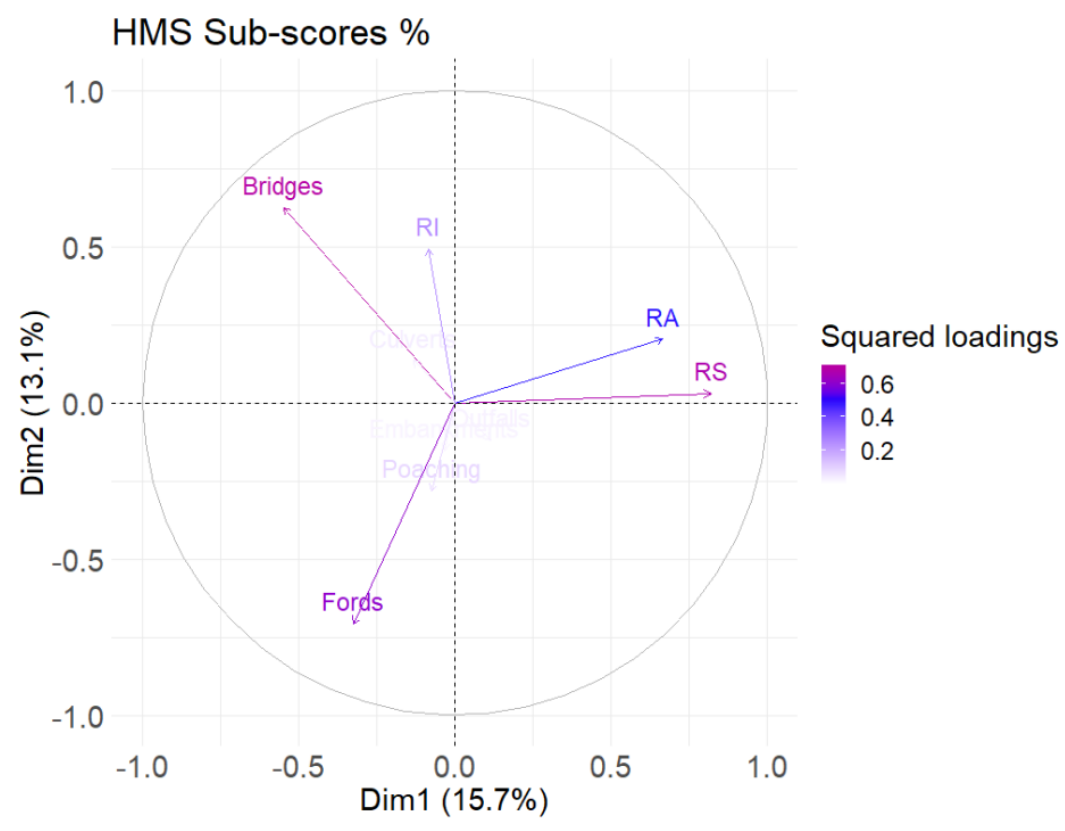

Figure 3. PCA factor map of the HMS sub-scores. Arrows represent the squared loadings of the variables. Color intensity is proportional to the value of the loading. Variables that are closer to the correlation circle contribute more to the principal components. RI means Bank Reinforcement, RS means Banks and Bed Resectioning and RA means Banks and Bed Realignment.

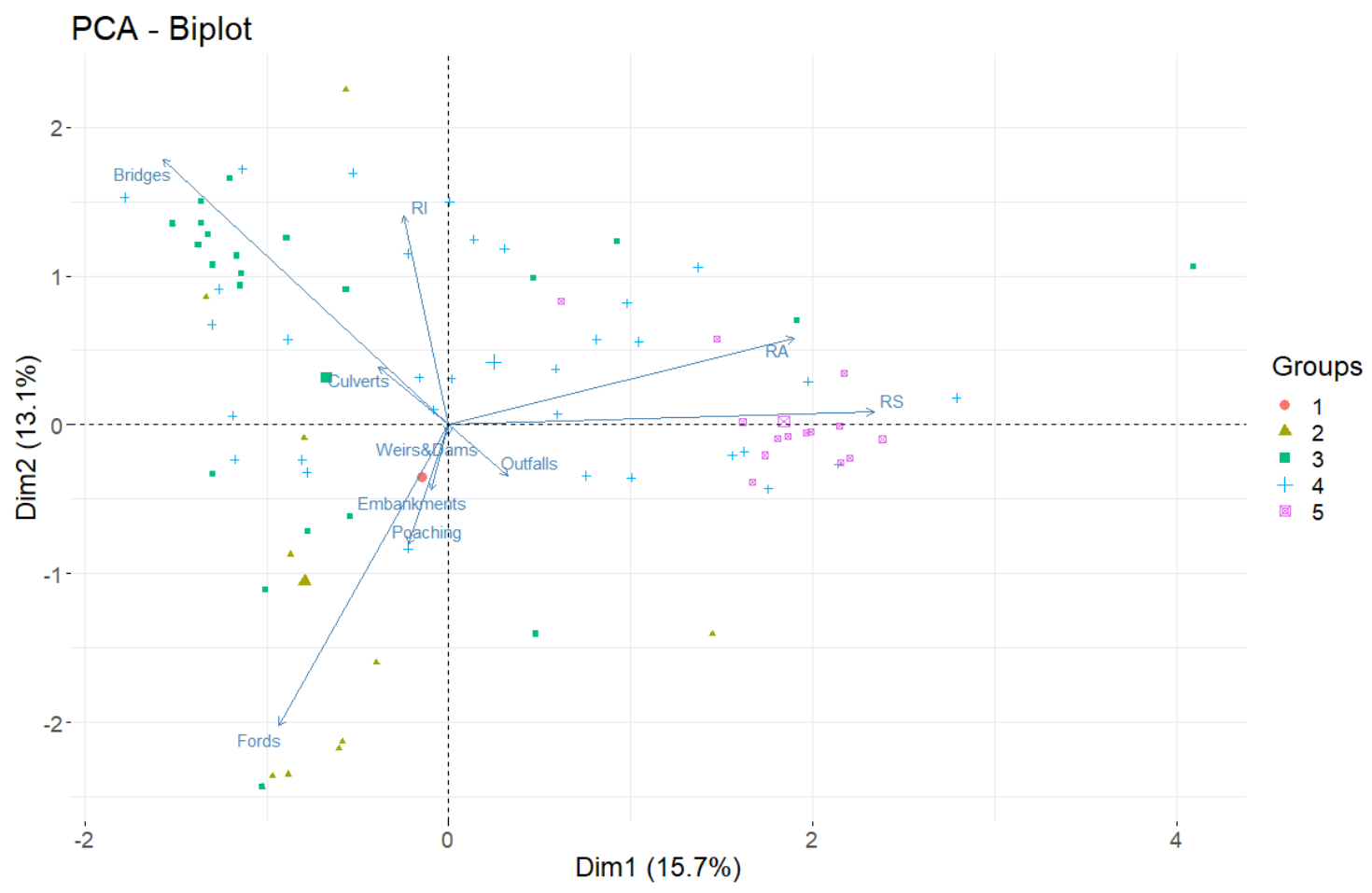

Figure 4. PCA biplot showing the examined river reaches grouped based on their HMS score and the loadings of the shares of the HMS sub-scores to the total HMS. Groups (1-5) correspond to HMS Classes where 1 = pristine/semi-natural, 2 = predominantly unmodified, 3 = obviously modified, $4=$ significantly modified and $5=$ severely modified.

\section{Conclusions}


This work presents the first results from a nationwide assessment of the hydromorphological status of Greek rivers in line with the WFD that will set the foundations for exploring the relationships between river hydromorphology, habitat diversity and ecological responses in Greek rivers.

In summary, our findings highlighted channel resectioning and realignment, and the presence of bridges and fords as the main features of hydromorphological alteration in the examined reaches. We assume that bank reprofiling and channel straightening, which are common flood protection measures for mitigating flood risk in agricultural catchments, are the main cause of longitudinal hydromorphological changes in Greek rivers. Conversely, bridges, fords and associated artificial structures and reinforcements in banks and channel are the most common cause for cross-sectional changes. Still, because a significant portion of the monitoring network sites are located very close to large bridges, there is a possibility of biased conclusions.

Furthermore, river typology plays a crucial role in identifying patterns of alterations and distinguishing the main hydromorphological features [12]. Thus, although our analysis is based on an extended dataset covering 106 river reaches from all over Greece, additional observations and measurements will allow us to produce more robust results and avoid biased conclusions. Nevertheless, the presented findings can provide valuable information regarding the extent of the total hydromorphological change and its' main components that may potentially aid water managers to formulate more effective management plans.

\section{References}

1. González del Tánago, M., Gurnell, A.M., Belletti, B., García de Jalón, D. Indicators of river system hydromorphological character and dynamics: understanding current conditions and guiding sustainable river management. Aquat. Sci. 2016, 78, 35-55. https://doi.org/10.1007/s00027-015-0429-0

2. Grizzetti, B., Pistocchi, A., Liquete, C., Udias, A., Bouraoui, F., Bund, W. Van De. Human pressures and ecological status of European rivers. Sci. Rep. 2017, 1-11. https://doi.org/10.1038/s41598-017-00324-3

3. Belletti, B., Nardi, L., Rinaldi, M., Poppe, M., Brabec, K., Bussettini, M., Comiti, F., Gielczewski, M., Golfieri, B., Hellsten, S., Kail, J., Marchese, E., Marcinkowski, P., Okruszko, T., Paillex, A., Schirmer, M., Stelmaszczyk, M., Surian, N. Assessing Restoration Effects on River Hydromorphology Using the Processbased Morphological Quality Index in Eight European River Reaches. Environ. Manage. 2018, 61, 69-84. https://doi.org/10.1007/s00267-017-0961-x

4. Belletti, B., Rinaldi, M., Buijse, A.D., Gurnell, A.M., Mosselman, E. A review of assessment methods for river hydromorphology. Environ. Earth Sci. 2014, 73, 2079-2100. https://doi.org/10.1007/s12665-014-3558-1

5. Fehér J., Gáspár J., Szurdiné-Veres K., Kiss A., Kristensen P., Peterlin M., Globevnik L., Kirn T., Semerádová S., Künitzer A., Stein U., Austnes K., Spiteri C., Prins T., Laukkonen E., Heiskanen A.S. Hydromorphological alterations and pressures in European rivers, lakes, transitional and coastal waters. Thematic assessment for EEA Water 2012 Report. European Topic Centre on Inland, Coastal and Marine Waters, Prague, ETC/ICM Technical Report 2/2012

6. Boon, P.J., Holmes, N.T.H., Raven, P.J. Developing standard approaches for recording and assessing river hydromorphology: The role of the European Committee for Standardization (CEN). Aquat. Conserv. Mar. Freshw. Ecosyst. 2010, 20, 55-61. https://doi.org/10.1002/aqc.1097

7. Stefanidis, Papaioannou, Markogianni, Dimitriou. Water Quality and Hydromorphological Variability in Greek Rivers: A Nationwide Assessment with Implications for Management. Water 2019, 11, 1680. https://doi.org/10.3390/w11081680

8. Raven, P J, Holmes, N T H, Dawson, F H, Everard, M. Quality assessment using River Habitat Survey data. Aquat. Conserv. Mar. Freshw. Ecosyst., 1998, 8, 405-424.

9. Lê, S.; Josse, J.; Husson, F. \{FactoMineR\}: A package for multivariate analysis. J. Stat. Softw. 2008, 25, 1-18

10. R Core Team. R: A Language and Environment for Statistical Computing; R Foundation for Statistical Computing: Vienna, Austria, 2018.

11. Erba, S., A. Buffagni, N. Holmes, M. O’Hare, P. Scarlett \& A. Stenico. Preliminary testing of River Habitat Survey features for the aims of the WFD hydromorphological assessment: an overview from the STAR Project. Hydrobiologia 2006, 566: 281-296.

12. Szoszkiewicz, K., Buffagni, A., Davy-Bowker, J., Lesny, J., Chojnicki, B.H., Zbierska, J., Staniszewski, R., Zgola, T. Occurrence and variability of River Habitat Survey features across Europe and the consequences 
for data collection and evaluation. Hydrobiologia 2006, 566, 267-280. https://doi.org/10.1007/s10750-0060090-7 